\section{A evolução da carga de causas externas no Brasil: uma comparação entre os anos de 1998 e 2008}

\author{
Evolution of the burden of injuries in Brazil: \\ a comparison between 1998 and 2008
}

\section{La evolución de la carga de causas externas en Brasil: una comparación entre los años} 1998 y 2008

\begin{abstract}
The objective of this study was to compare estimates of external causes based on the Global Burden of Disease in Brazil Study for the years 1998 and 2008. Methods included estimation of $D A L Y s$ (disability-adjusted life years) and YLL (years of life lost), based on the methodology proposed in the Global Burden of Disease Study. Calculation of YLD (years lived with disability) required applying the same methodology in both years, with the 2008 methodology as the standard. Although external causes accounted for some 10\% of total DALYs in both years, their internal distribution showed marked differences between regions of Brazil, with a decrease in the Southeast and increase in the North and Northeast. There was an increase in intentional causes, and YLLs accounted for the largest share of DALYs. The results can support new policies and/or improve existing ones to address external causes.
\end{abstract}

Accidents; Homicide; External Causes; Cost of Illness
Luiz Villarinho Pereira Mendes 1

Mônica Rodrigues Campos 1

Vanessa dos Reis von-Doellinger 1

Jurema Corrêa da Mota 1

Thiago Góes Pimentel 1

Joyce Mendes de Andrade Schramm ${ }^{1}$

\section{Resumo}

O objetivo foi comparar as estimativas das causas externas provenientes do estudo Carga Global de Doenças, entre os anos 1998 e 2008. A estimação do DALY (disability-adjusted life year) e do YLL (years of life lost) foi baseada em metodologia do estudo Carga Global de Doenças. Para o cálculo do YLD (years lived with disability), foram incluídas informações sobre atendimentos em emergências. Para comparabilidade, fez-se necessária a aplicação da mesma metodologia nos dois momentos analisados, tendo sido a mais recente eleita como padrão de referência. Em ambos os anos as causas externas foram responsáveis por cerca de $10 \%$ do total do DALY. Entretanto, sua distribuição interna apresentou marcada diferença entre as regiões do Brasil, com queda no Sudeste e aumento no Norte e Nordeste. Houve aumento das causas intencionais e o DALY se tornou mais letal (maior parcela de YLL). Espera-se que tais resultados balizem a formulação de políticas elou o aprimoramento das já existentes com vistas ao efetivo enfrentamento das causas externas.

Acidentes; Homicídio; Causas Externas; Efeitos Psicossociais da Doença 


\section{Introdução}

O Brasil, nas últimas décadas, vem experimentando mudanças em seu perfil epidemiológico bem documentadas na literatura 1,2. A queda na mortalidade e o aumento da expectativa de vida como decorrência de avanços na medicina, nas políticas de saúde, no saneamento básico, dentre outros, vêm sendo mitigados pela elevação das doenças não transmissíveis e das causas externas. As últimas tiveram crescimento vertiginoso nacionalmente, desde a década de 1980 3, passando a figurar entre as três maiores causas de mortalidade e assim têm se mantido até os dias de hoje (Departamento de Informática do SUS. Informações de saúde (TABNET). http://www2. datasus.gov.br/DATASUS/index.php?area=02, acessado em 22/Out/2103).

As estimativas - baseadas nos sistemas de informação para 2012 - mostram que aproximadamente 152 mil pessoas morreram e quase 1 milhão foram internadas por causas externas (Departamento de Informática do SUS. Informações de saúde (TABNET). http://www2.datasus. gov.br/DATASUS/index.php?area=02, acessado em 22/Out/2103). Entre os sobreviventes, muitos ficam incapacitados temporária ou permanentemente, com perda da capacidade laborativa e da qualidade de vida, provocando grande impacto no sistema de saúde e nas condições de vida da população ${ }^{4}$.

Em razão da diversidade de agravos abarcados pelo grupo das causas externas, a literatura científica nacional e internacional se debruça em diferentes recortes que consideram a natureza da injúria e o grupo populacional mais vulnerável. Os acidentes de trânsito e os homicídios e suicídios são mais frequentemente estudados com enfoque na população de jovens 5,6. As quedas têm sido mais abordadas entre idosos 7,8, e as injúrias não intencionais, sobretudo os acidentes domésticos, são mais analisados nas crianças e adolescentes 9,10 .

No Brasil, as causas externas têm sido estudadas mediante a análise da mortalidade $5,6,11$ por meio do Sistema de Informações sobre Mortalidade (SIM) pela qualidade e facilidade de obtenção dos dados. Dentre as fontes disponíveis para estudo de morbidade, destaca-se o Sistema de Informações Hospitalares (SIH) vinculado ao Sistema Único de Saúde (SUS) que, após 1997, passou a disponibilizar dados sobre internações no setor público relacionadas a esses agravos. Com efeito, foi então possível a realização de estudos de representatividade nacional 12,13. Especificamente quanto aos atendimentos em emergências, uma iniciativa importante foi a realização do inquérito da Vigilância de Violências e Aciden- tes (VIVA Inquérito 2009) em serviços sentinela de urgência e emergência 14 .

A despeito da importância que a análise simples das taxas de morbimortalidade possa ter para a compreensão do impacto das causas externas, registra-se a necessidade de um método que compute com maior acurácia o quanto esses agravos efetivamente influenciam as condições de saúde da população, considerando aspectos como gravidade e duração das lesões, faixa etária, qualidade de vida etc.

Nesse sentido, é de extrema utilidade o indicador DALY (disability-adjusted life year - anos de vida perdidos por morte prematura ajustados por incapacidade), desenvolvido por Murray \& Lopez 15 em meados da década de 1990, no contexto do estudo Global Burden of Disease (GBD). Esse indicador se divide em dois componentes: (1) mortalidade - estimativa dos anos de vida perdidos por morte prematura (YLL - years of life lost) e (2) morbidade - estimativa dos anos de vida vividos com incapacidade (YLD - years lived with disability).

Os anos de vida perdidos por agravos/sequelas são estimados por meio de parâmetros clínico-epidemiológicos: incidência, prevalência, letalidade, remissão, duração e proporção de casos tratados. Os agravos/sequelas, por sua vez, são subdivididos em grandes grupos de análise: (1) doenças transmissíveis, condições maternas/ perinatais e condições nutricionais; (2) doenças não transmissíveis; e (3) causas externas 15.

Passadas quase três décadas de seu surgimento, os estudos de carga global de doença 15,16 têm incorporado atualizações e refinamentos metodológicos 17,18. No Brasil, foram realizadas duas edições do estudo: a primeira referiu-se ao ano de 1998; a segunda, a 2008 19. Na mais atual foram implementados aportes metodológicos tanto para correção dos dados de mortalidade, quanto para estimação dos parâmetros clínicoepidemiológicos para a morbidade. Neste último caso, particularmente para as causas externas, houve importantes modificações, com a incorporação dos dados do VIVA Inquérito 200914 sobre atendimentos realizados em emergências.

O objetivo deste artigo é apresentar as estimativas do DALY, YLL e YLD para as causas externas, comparativamente nos anos 1998 e 2008, segundo faixa etária, sexo e macrorregiões do Brasil.

\section{Materiais e métodos}

Para estimação da carga de doença relacionada às causas externas, foi utilizado o agrupamento das causas, segundo o capítulo XX da 10a revi- 
são da Classificação Internacional de Doenças (CID-10) 20, em não intencionais (IIIA) e intencionais (IIIB). O primeiro grupo (IIIA) é composto por acidente de trânsito (IIIA01;V01-V89, Y85), intoxicação acidental por exposição (IIIA02; X40-X49), quedas (IIIA03; W00-W19), exposição ao fogo/frio - queimaduras/geladuras (IIIA04; X00-X09), afogamento e submersão (IIIA05; W65-W74), outras causas não intencionais (IIIA06; V90-V99; W20-W64; W75-W99; X10-X39; X50-X59;Y86) e complicações da assistência médica (IIIA07; Y40-Y84;Y88). Já o segundo grupo (IIIB), é constituído por lesões autoprovocadas/suicídio (IIIB01; X60-X84), homicídios/agressões (IIIB02; X85-Y09; Y87) e guerra/intervenção legal (IIIB03; Y35-Y36).

Para o componente de mortalidade (YLL), que mede, basicamente, a expectativa de vida a partir da idade do óbito dada sua causa, a fonte de dados utilizada foi o SIM, no período de referência. Calculou-se a expectativa de vida ao nascer por sexo, faixa etária e macrorregiões do país, conforme metodologia desenvolvida Coale \& Guo ${ }^{21}$ e apresentada nos relatórios dos estudos de carga de doença Brasil - 199822 e 200823.

Dados do SIH-SUS (Departamento de Informática do SUS. Informações de saúde (TABNET). http://www2.datasus.gov.br/DATASUS/index. php?area=02, acessado em 22/Out/2103) foram utilizados para a construção do componente de morbidade (YLD) pela seleção dos grupos da CID-10 acima referidos para causas externas nos diagnósticos principal e secundário. Realizou-se desagregação dos diferentes parâmetros clínicoepidemiológicos aferidos, além do motivo de cobrança e do procedimento realizado para internações no período de referência, excluindo-se os óbitos e as internações de longa permanência (AIH tipo 5), segundo estratos sociodemográficos, tais como sexo, idade e macrorregiões e diagnósticos (principal e secundário). Foi aplicado o fator de cobertura SUS do ano de referência para estimar as internações realizadas no setor privado 25 .

Foi considerada a média de internações e óbitos no triênio 1997, 1998 e 1999 para a estimativa de carga de doença de 1998 e a média dessas mesmas informações no triênio 2007, 2008 e 2009 para a estimativa de 2008.

Para comparar o perfil da carga de causas externas dos anos de 1998 e 2008, aplicou-se a mesma metodologia nos dois momentos analisados, assumindo-se a estimativa de 2008 como padrão de referência. Essa escolha deveu-se ao fato de que a metodologia de 2008 mensurou o impacto das emergências em âmbito nacional, com uso do VIVA Inquérito ${ }^{14}$, cenário não disponível no estudo de 1998.
O VIVA Inquérito 14 registrou vítimas de causas externas que procuraram atendimento pela primeira vez nos serviços de urgência e emergência em 23 capitais, no Distrito Federal e 12 municípios selecionados, totalizando 136 serviços de urgência e emergência. Além disso, registrou ainda a eventual evolução ou não do caso à internação. No geral, segundo esse inquérito, em 2009, para todas as causas externas, apenas $9,6 \%$ dos atendidos foram internados. Os procedimentos detalhados para esse cálculo estão no diário de bordo do estudo Carga Global de Doença no Brasil (GBD Brasil) de 200819.

Apenas para estimativa da duração e dos pesos de incapacidade, que foram utilizados os procedimentos aplicados ao estudo GBD Brasil 1998 $15,16,17,18,19,20,21,22$. Aplicou-se então uma taxa de desconto de $3 \%$ e não foi utilizado fator de ponderação da idade 16. Maiores informações sobre a metodologia adotada podem ser consultadas em artigo redigido especificamente para este fim 19.

As comparações dos resultados de 1998 e 2008 foram feitas mediante análise descritiva, e a carga de doença foi analisada em termos de taxas por mil habitantes, por sexo, faixa etária, causas e macrorregiões do Brasil. Para melhor expressar a variação entre os anos foram utilizados os símbolos $\Delta_{\text {Abs }}$ e $\Delta_{\%}$ que representam, respectivamente, as diferenças absolutas entre as taxas dos anos 2008 e 1998 e o percentual de variação das taxas entre eles.

Quantos aos aspectos éticos para a realização deste estudo, todas as bases de dados foram obtidas para os anos de 1997-1999 e 2007-2009, diretamente da página do Departamento de Informática do SUS (Informações de saúde TABNET. http://www2.datasus.gov.br/DATASUS/ index.php?area=02, acessado em 22/Out/2103), exceto os dados do VIVA Inquérito, que foram disponibilizados pela diretoria do Departamento de Análise de Situação de Saúde do Ministério da Saúde, após assinatura do termo de concessão e confidencialidade pela coordenação do projeto Carga Global de Doença e subsequente aprovação no Comitê de Ética em Pesquisa da Escola Nacional de Saúde Pública Sergio Arouca, Fundação Oswaldo Cruz (CAAE: 0054.0.031.000-11).

\section{Resultados}

No Brasil, as causas externas foram responsáveis por aproximadamente $10 \%$ do total da carga de doença estimada tanto para 1998 quanto para 2008. Nesse período, houve aumento na parcela do DALY para as causas intencionais (de $42 \%$ para $46 \%$ ) e consequente redução entre as acidentais (de 58\% para 54\%) (Tabela 1). A seguir, para 
Tabela 1

Distribuição das taxas de DALY (disability-adjusted life year), YLL (years of life lost), YLD (years lived with disability) de causas externas segundo sexo. Brasil, 1998 e 2008.

\begin{tabular}{|c|c|c|c|c|c|c|c|c|c|c|c|c|}
\hline \multirow[t]{2}{*}{ Causas externas } & \multicolumn{4}{|c|}{ Homens } & \multicolumn{4}{|c|}{ Mulheres } & \multicolumn{4}{|c|}{ Total } \\
\hline & 1998 & 2008 & $\Delta_{\text {absoluto }}$ & $\Delta_{\%}$ & 1998 & 2008 & $\Delta_{\text {absoluto }}$ & $\Delta_{\%}$ & 1998 & 2008 & $\Delta_{\text {absoluto }}$ & $\Delta_{\%}$ \\
\hline \multicolumn{13}{|l|}{ Taxa DALY/1.000 habitantes } \\
\hline Acidente de trânsito & 88,7 & 89,7 & 1,0 & 1,1 & 22,9 & 19,5 & $-3,3$ & $-14,6$ & 55,3 & 54,0 & $-1,3$ & $-2,4$ \\
\hline Envenenamento & 1,2 & 0,8 & $-0,3$ & $-29,5$ & 0,7 & 0,4 & $-0,3$ & $-45,0$ & 0,9 & 0,6 & $-0,3$ & $-35,4$ \\
\hline Queda & 22,7 & 21,5 & $-1,2$ & $-5,4$ & 9,6 & 9,5 & 0 &,- 5 & 16,0 & 15,4 &,- 7 & $-4,1$ \\
\hline Queimadura & 5,3 & 2,9 & $-2,4$ & $-45,6$ & 3,3 & 1,4 & $-1,9$ & $-56,2$ & 4,3 & 2,1 & $-2,1$ & $-49,8$ \\
\hline Afogamento & 19,3 & 14,8 & $-4,5$ & $-23,4$ & 3,5 & 2,5 & $-1,0$ & $-28,3$ & 11,3 & 8,5 & $-2,7$ & $-24,4$ \\
\hline Outras não intencionais & 42,5 & 25,3 & $-17,2$ & $-40,5$ & 16,4 & 10,4 & $-5,9$ & $-36,3$ & 29,2 & 17,7 & $-11,5$ & $-39,4$ \\
\hline Complicação médica & 2,0 & 1,6 & $-0,3$ & $-17,2$ & 1,5 & 1,4 & $-0,1$ & $-7,5$ & 1,7 & 1,5 & $-0,2$ & $-13,0$ \\
\hline Suicídio & 19,3 & 20,4 & 1,1 & 5,6 & 5,4 & 5,6 & 0,2 & 3,5 & 12,3 & 12,9 & 0,6 & 4,9 \\
\hline Homicídio/Violência & 137,4 & 134,6 & $-2,8$ & $-2,1$ & 13,4 & 11,8 & $-1,6$ & $-12,0$ & 74,6 & 72,1 & $-2,4$ & $-3,3$ \\
\hline Não intencionais & 181,6 & 156,5 & $-25,1$ & $-13,8$ & 57,8 & 45,2 & $-12,6$ & $-21,8$ & 118,8 & 99,9 & $-19,0$ & $-15,9$ \\
\hline Intencionais & 156,9 & 156,6 & $-0,3$ & $-0,2$ & 18,9 & 17,4 & $-1,4$ & $-7,5$ & 86,9 & 85,8 & $-1,1$ & $-1,3$ \\
\hline Total causas externas & 338,4 & 313,1 & $-25,4$ & $-7,5$ & 76,6 & 62,6 & $-14,0$ & $-18,3$ & 205,7 & 185,7 & $-20,0$ & $-9,7$ \\
\hline \multicolumn{13}{|l|}{ Taxa YLL/1.000 habitantes } \\
\hline Acidente de trânsito & 81,9 & 85,4 & 3,5 & 4,3 & 20,1 & 18,2 & $-1,9$ & $-9,4$ & 50,6 & 51,2 & 6 & 1,3 \\
\hline Envenenamento & 0,9 & 0,7 & $-0,2$ & $-24,3$ & 0,5 & 0,3 & $-0,2$ & $-35,9$ & 0,7 & 0,5 & $-0,2$ & $-28,4$ \\
\hline Queda & 9,4 & 11,2 & 1,8 & 19,2 & 2,0 & 3,6 & 1,6 & 78,5 & 5,7 & 7,4 & 1,7 & 29,8 \\
\hline Queimadura & 2,6 & 1,8 & $-0,9$ & $-32,7$ & 1,6 & 0,8 & $-0,8$ & $-48,7$ & 2,1 & 1,3 & $-0,8$ & $-39,0$ \\
\hline Afogamento & 19,2 & 14,7 & $-4,4$ & $-23,2$ & 3,5 & 2,5 & $-1,0$ & $-28,3$ & 11,2 & 8,5 & $-2,7$ & $-24,1$ \\
\hline Outras não intencionais & 29,4 & 15,1 & $-14,3$ & $-48,7$ & 7,1 & 4,2 & $-3,0$ & $-41,7$ & 18,1 & 9,5 & $-8,6$ & $-47,4$ \\
\hline Complicação médica & 1,0 & 0,8 & $-0,2$ & $-20,0$ & 1,0 & 0,9 & $-0,1$ & $-9,8$ & 1,0 & 0,9 & $-0,1$ & $-14,9$ \\
\hline Suicídio & 18,9 & 20,3 & 1,4 & 7,5 & 5,1 & 5,5 & 0,4 & 8,0 & 11,9 & 12,8 & 0,9 & 7,4 \\
\hline Homicídio/Violência & 135,5 & 133,2 & $-2,3$ & $-1,7$ & 12,8 & 11,4 & $-1,3$ & $-10,5$ & 73,3 & 71,3 & $-2,0$ & $-2,8$ \\
\hline Não intencionais & 144,4 & 129,7 & $-14,7$ & $-10,2$ & 35,8 & 30,5 & $-5,3$ & $-14,8$ & 89,4 & 79,3 & $-10,1$ & $-11,3$ \\
\hline Intencionais & 154,5 & 155,1 & 0,6 & 0,4 & 17,9 & 17,0 &,- 9 & $-5,2$ & 85,2 & 84,8 & $-0,4$ & $-0,5$ \\
\hline Total causas externas & 298,9 & 284,8 & $-14,1$ & $-4,7$ & 53,7 & 47,5 & $-6,2$ & $-11,6$ & 174,6 & 164,1 & $-10,5$ & $-6,0$ \\
\hline \multicolumn{13}{|l|}{ Taxa YLD/1.000 habitantes } \\
\hline Acidente de trânsito & 6,8 & 4,3 & $-1,9$ & $-37,4$ & 2,8 & 1,3 & $-1,4$ & $-51,8$ & 4,8 & 2,8 & $-2,0$ & $-41,8$ \\
\hline Envenenamento & 0,2 & 0,1 & $-0,2$ & $-50,7$ & 0,2 & 0,1 & $-0,1$ & $-66,4$ & 0,2 & 0,1 & $-0,1$ & $-58,2$ \\
\hline Queda & 13,3 & 10,3 & 1,6 & $-22,9$ & 7,5 & 5,9 & $-1,6$ & $-21,8$ & 10,4 & 8,0 & $-2,3$ & $-22,6$ \\
\hline Queimadura & 2,7 & 1,1 &,- 8 & $-58,4$ & 1,7 & 0,6 & $-1,1$ & $-63,5$ & 2,2 & 0,9 & $-1,3$ & $-60,4$ \\
\hline Afogamento & 0,1 & 0,0 & $-1,0$ & $-71,7$ & 0 & 0,0 & 0,0 & $-41,9$ & 0,1 & 0,0 & 0,0 & $-66,4$ \\
\hline Outras não intencionais & 13,1 & 10,2 & $-3,0$ & $-22,1$ & 9,2 & 6,3 & $-3,0$ & $-32,1$ & 11,1 & 8,2 & $-2,9$ & $-26,4$ \\
\hline Complicação médica & 1,0 & 0,8 & $-0,1$ & $-14,2$ & 0,5 & 0,5 & 0,0 & $-2,7$ & 0,7 & 0,6 & $-0,1$ & $-10,3$ \\
\hline Suicídio & 0,5 & 0,1 & 0,4 & $-68,9$ & 0,3 & 01 & $-0,2$ & $-67,0$ & 0,4 & 0,1 & $-0,3$ & $-68,1$ \\
\hline Homicídio/Violência & 1,9 & 1,3 & $-1,3$ & $-29,0$ & 0,7 & 0,4 & $-0,3$ & $-42,5$ & 1,3 & 0,8 & $-0,4$ & $-32,7$ \\
\hline Não intencionais & 37,1 & 26,8 & $-5,3$ & $-27,9$ & 22,0 & 14,7 & $-7,3$ & $-33,1$ & 29,4 & 20,6 & $-8,8$ & $-29,9$ \\
\hline Intencionais & 2,4 & 1,5 & $-0,9$ & $-37,2$ & 1,0 & 0,5 & $-0,5$ & $-50,6$ & 1,7 & 1,0 & $-0,7$ & $-41,3$ \\
\hline Total causas externas & 39,5 & 28,3 & $-6,2$ & $-28,5$ & 22,9 & 15,2 & $-7,8$ & $-33,9$ & 31,1 & 21,6 & $-9,5$ & $-30,6$ \\
\hline
\end{tabular}

os anos de 1998 e 2008, serão apresentadas as taxas de YLL, YLD e DALY, estratificadas por região, sexo e faixa etária, bem como seus diferenciais absolutos e relativos.

\section{Análise por regiões}

Para os anos de 1998 e 2008, no Brasil, em ambos os sexos, não houve alteração quanto ao ranking do DALY de causas externas, sendo os homicí- 
dios/agressões (74,6 e 72,1) seguidos dos acidentes de trânsito $(55,3$ e 54,0) e "outras não intencionais” $(29,2$ e 17,7$)$ as causas com maiores taxas de anos de vida perdidos. Para o YLL, os acidentes de trânsito (50,6 e 51,2) e os homicídios/agressões $(73,3$ e 71,3$)$ figuraram com as taxas mais elevadas nos dois anos, entretanto "outras não intencionais” (18,1 e 9,5), que ocupava terceira posição em 1998, deu lugar ao suicídio em 2008 (11,9 e 12,8). As taxas de YLD foram, em ambos os anos, mais elevadas entre as causas não intencionais $(29,4$ e 20,6), sendo as "outras causas não intencionais" (11,1 e 8,2$)$, as quedas $(10,4$ e 8,0$)$ e os acidentes de trânsito $(4,8$ e 2,8) os grupos de causas com as maiores taxas identificadas (Tabela 1).

Em relação à variação nas taxas de DALY, no Brasil, no período 1998-2008, com exceção do suicídio $\left(\Delta_{\text {absoluto }}=0,6 ; \Delta_{\%}=4,9\right)$, todos os grupos de causas externas tiveram redução nas taxas, implicando queda no grupo como um todo $\left(\Delta_{\text {absoluto }}=-20,0 ; \Delta_{\%}=-9,7\right)$. Porém, é importante ressaltar que essa diminuição apenas foi expressiva para as categorias "outras não intencionais" $\left(\Delta_{\text {absoluto }}=-11,5 ; \Delta_{\%}=-39,4\right) \mathrm{e}$ "todas as causas não intencionais" ( $\Delta_{\text {absoluto }}=-19,0 ; \Delta_{\%}=-15,9$ ), tendo sido inferior a 3 pontos nos valores absolutos das taxas de todas as demais categorias. Quanto às taxas de YLL, na mesma direção do DALY, também caíram no total das causas externas $\left(\Delta_{\text {absoluto }}=-10,5 ; \Delta_{\%}=-6,0\right)$, e essa queda apenas foi expressiva para "outras não intencionais" $\left(\Delta_{\text {absoluto }}=-8,6 ; \Delta_{\%}=-47,4\right) \mathrm{e}$ "todas as causas não intencionais" ( $\left.\Delta_{\text {absoluto }}=-10,1 ; \Delta_{\%}=-11,3\right)$. No entanto, sofreram um aumento para as quedas ( $\left.\Delta_{\text {absoluto }}=1,7 ; \Delta_{\%}=29,8\right)$, os suicídios $\left(\Delta_{\text {absoluto }}\right.$ $\left.=0,9 ; \Delta_{\%}=7,4\right)$ e acidentes de trânsito $\left(\Delta_{\text {absoluto }}=\right.$ 0,$\left.6 ; \Delta_{\%}=1,3\right)$. Quanto ao YLD, ele teve diminuição em todos os grupos de causas $\left(\Delta_{\text {absoluto }}=-9,5 ; \Delta_{\%}\right.$ $=-30,6)$. Destaca-se que, em virtude das taxas de YLD para causas externas serem menores comparativamente ao YLL e DALY, essas reduções implicaram variações percentuais muito mais elevadas, de -10,3\% (complicações da assistência médica) a -68,1\% (suicídio) (Tabela 1).

A estratificação por regiões apresentada na Tabela 2 mostra que as reduções identificadas no DALY foram, sobretudo, impulsionadas pelo Sudeste $\left(\Delta_{\text {absoluto }}=-68,5 ; \Delta_{\%}=-27,9\right)$ e, em

Tabela 2

Distribuição das taxas de DALY (disability-adjusted life year) do total das causas externas, homicídios e acidentes de trânsito, segundo sexo e macrorregiões. Brasil, 1998 e 2008.

\begin{tabular}{|c|c|c|c|c|c|c|c|c|c|c|c|c|}
\hline \multirow{2}{*}{$\begin{array}{l}\text { DALY/1.000 habitanes/ } \\
\text { Macrorregiões }\end{array}$} & \multicolumn{4}{|c|}{ Homens } & \multicolumn{4}{|c|}{ Mulheres } & \multicolumn{4}{|c|}{ Total } \\
\hline & 1998 & 2008 & $\Delta_{\text {absoluto }}$ & $\Delta_{\%}$ & 1998 & 2008 & $\Delta_{\text {absoluto }}$ & $\Delta_{\%}$ & 1998 & 2008 & $\Delta_{\text {absoluto }}$ & $\Delta_{\%}$ \\
\hline \multicolumn{13}{|l|}{ Total causas externas } \\
\hline Norte & 260,4 & 306,6 & 46,2 & 17,7 & 69,3 & 59,6 & $-9,7$ & $-13,9$ & 166,2 & 184,5 & 18,3 & 11,0 \\
\hline Nordeste & 261,5 & 325,7 & 64,1 & 24,5 & 64,2 & 54,6 & $-9,6$ & $-14,9$ & 160,7 & 187,7 & 26,9 & 16,8 \\
\hline Sudeste & 412,1 & 296,1 & $-116,1$ & $-28,2$ & 84,3 & 63,4 & $-21,0$ & $-24,9$ & 245,4 & 176,8 & $-68,5$ & $-27,9$ \\
\hline Sul & 314,1 & 319,6 & 5,5 & 1,8 & 83,7 & 71,6 & $-12,0$ & $-14,4$ & 197,8 & 193,9 & $-3,9$ & $-2,0$ \\
\hline Centro-oeste & 371,6 & 356,1 & $-15,5$ & $-4,2$ & 95,4 & 75,1 & $-20,3$ & $-21,3$ & 233,6 & 214,4 & $-19,2$ & $-8,2$ \\
\hline Brasil & 338,4 & 313,1 & $-25,4$ & $-7,5$ & 76,6 & 62,6 & $-14,0$ & $-18,3$ & 205,7 & 185,7 & $-20,0$ & $-9,7$ \\
\hline \multicolumn{13}{|l|}{ Acidentes de trânsito } \\
\hline Norte & 64,6 & 73,3 & 8,7 & 13,4 & 18,3 & 18,7 &, 4 & 2,3 & 41,8 & 46,3 & 4,5 & 10,9 \\
\hline Nordeste & 60,0 & 81,3 & 21,3 & 35,5 & 14,4 & 15,8 & 1,5 & 10,3 & 36,7 & 48,0 & 11,3 & 30,7 \\
\hline Sudeste & 100,0 & 89,2 & $-10,9$ & $-10,9$ & 25,8 & 19,2 & $-6,6$ & $-25,7$ & 62,2 & 53,3 & $-9,0$ & $-14,4$ \\
\hline Sul & 110,1 & 104,6 & $-5,5$ & $-5,0$ & 29,0 & 23,9 & $-5,1$ & $-17,6$ & 69,2 & 63,7 & $-5,5$ & $-7,9$ \\
\hline Centro-oeste & 116,2 & 112,9 & $-3,3$ & $-2,8$ & 32,0 & 28,2 & $-3,8$ & $-11,9$ & 74,1 & 70,1 & $-4,0$ & $-5,3$ \\
\hline Brasil & 88,7 & 89,7 & 1,0 & 1,1 & 22,9 & 19,5 & $-3,3$ & $-14,6$ & 55,3 & 54,0 & $-1,3$ & $-2,4$ \\
\hline \multicolumn{13}{|l|}{ Homicídios } \\
\hline Norte & 93,9 & 148,0 & 54,1 & 57,6 & 11,3 & 12,4 & 1,0 & 9,2 & 53,2 & 81,0 & 27,8 & 52,2 \\
\hline Nordeste & 100,9 & 166,0 & 65,1 & 64,5 & 8,9 & 11,9 & 3,0 & 33,9 & 53,9 & 87,5 & 33,6 & 62,4 \\
\hline Sudeste & 193,0 & 116,0 & $-77,0$ & $-39,9$ & 17,7 & 11,3 & $-6,3$ & $-35,8$ & 103,8 & 62,4 & $-41,4$ & $-39,9$ \\
\hline Sul & 73,2 & 113,6 & 40,4 & 55,2 & 9,5 & 11,5 & 1,9 & 20,4 & 41,1 & 61,8 & 20,8 & 50,5 \\
\hline Centro-oeste & 133,0 & 147,8 & 14,8 & 11,1 & 16,7 & 14,5 & $-2,2$ & $-13,0$ & 74,9 & 80,6 & 5,7 & 7,6 \\
\hline Brasil & 137,4 & 134,6 & $-2,8$ & $-2,1$ & 13,4 & 11,8 & $-1,6$ & $-12,0$ & 74,6 & 72,1 & $-2,4$ & $-3,3$ \\
\hline
\end{tabular}


menor grau, pelo Centro-oeste $\left(\Delta_{\text {absoluto }}=-19,2\right.$; $\left.\Delta_{\%}=-8,2\right)$ e Sul $\left(\Delta_{\text {absoluto }}=-3,9 ; \Delta_{\%}=-2,0\right)$. Por outro lado, as regiões Nordeste $\left(\Delta_{\text {absoluto }}=26,9 ; \Delta_{\%}=\right.$ $16,8)$ e Norte $\left(\Delta_{\text {absoluto }}=18,3 ; \Delta_{\%}=11\right)$ apresentaram expressivo acréscimo nessas taxas.

A carga relacionada aos homicídios/agressões teve aumento expressivo nas regiões Nordeste $\left(\Delta_{\text {absoluto }}=33,6 ; \Delta_{\%}=62,4\right)$, Norte $\left(\Delta_{\text {absoluto }}=\right.$ 27,$\left.8 ; \Delta_{\%}=52,2\right)$ e Sul $\left(\Delta_{\text {absoluto }}=20,8 ; \Delta_{\%}=50,5\right)$, reduzindo unicamente, e de forma bem marcada, no Sudeste $\left(\Delta_{\text {absoluto }}=-41,4 ; \Delta_{\%}=-39,9\right)$. Já os acidentes de trânsito aumentaram e reduziram de forma relevante nas regiões Nordeste $\left(\Delta_{\text {absoluto }}=\right.$ 11,$\left.3 ; \Delta_{\%}=30,7\right)$ e Sudeste $\left(\Delta_{\text {absoluto }}=-9,0 ; \Delta_{\%}=\right.$ $-14,4)$, respectivamente.

A Figura 1 permite observar que as regiões Norte e Nordeste, responsáveis por $27,8 \%$ do DALY de causas externas no ano de 1998 passaram em 2008 a representar 36,2\%, um aumento de $8,4 \%$. Na direção contrária está o Sudeste que em 1998 concentrava 50,4\% do DALY e passou em 2008 a figurar com $40,3 \%$, reduzindo $10 \%$. No que concerne à composição do DALY, ocorreu uma diminuição na parcela do YLD e consequente aumento na do YLL para todas as regiões do país, ou seja, no período analisado, intensificou-se ainda mais o elevado padrão de letalidade identificado para as causas externas no Brasil e todas as suas regiões.

\section{Análise por sexo}

No Brasil, a redução identificada nas taxas de DALY de causas externas ocorreu tanto entre os homens $\left(\Delta_{\text {absoluto }}=-25,4 ; \Delta_{\%}=-7,5\right)$ quanto entre as mulheres $\left(\Delta_{\text {absoluto }}=-14,0 ; \Delta_{\%}=-18,3\right)$, sendo as "outras causas não intencionais" as maiores responsáveis por essa queda em ambos os sexos. Contudo, chama a atenção que essas variações não foram totalmente homogêneas, havendo, por exemplo, aumento das taxas de acidentes de trânsito entre os homens $\left(\Delta_{\text {absoluto }}=1,0 ; \Delta_{\%}=\right.$ $1,1)$ e redução entre as mulheres $\left(\Delta_{\text {absoluto }}=-3,3\right.$; $\Delta_{\%}=-14,6$ ) (Tabela 1). Também foi identificado um acirramento do perfil predominantemente masculino do DALY de causas externas em que a razão de sexo para os homens passou de 4,4 no ano de 1998 para 5,0 em 2008. Ainda com relação às taxas de DALY, os grupos de causas externas que apresentaram maior razão de sexo para os homens, tanto em 1998 quanto em 2008 foram os homicídios/agressões (10,2 e 11,4, respectivamente) seguidos dos afogamentos (5,5 e 5,9). Vale destacar ainda que, para os acidentes de trânsito, a razão de sexo $(3,9$ a 4,6) manteve-se constante no período (Tabela 1 e Figura 2).

O perfil identificado para o YLL, como esperado, é bem próximo do exposto para DALY quanto à estratificação por sexo, mas para o YLD registram-se razões de sexo bem menores, sendo os homicídios/agressões (2,9 e 3,6) e os afogamentos $(4,7$ e 2,3) as causas em que se verificam maiores assimetrias (Tabela 1 ).

No que se refere à estratificação das taxas do DALY de causas externas por regiões, entre os homens, chama a atenção os aumentos acentuados no Nordeste $\left(\Delta_{\text {absoluto }}=64,1 ; \Delta_{\%}=24,5\right)$ e Norte $\left(\Delta_{\text {absoluto }}=46,2 ; \Delta_{\%}=17,7\right)$; aconteceu queda apenas no $\operatorname{Sudeste}\left(\Delta_{\text {absoluto }}=-116,1 ; \Delta_{\%}=-28,2\right)$ e Centro-oeste $\left(\Delta_{\text {absoluto }}=-15,5 ; \Delta_{\%}=-4,2\right)$. Já entre as mulheres, as taxas de DALY reduziram em todas as regiões do país, com destaque para o Sudeste $\left(\Delta_{\text {absoluto }}=-21,0 ; \Delta_{\%}=-24,9\right)$ e Centro-oeste $\left(\Delta_{\text {absoluto }}=-20,3 ; \Delta_{\%}=-21,3\right)$. Considerando as taxas de DALY relacionadas aos acidentes de trânsito, elas caíram em todas as regiões, exceto Norte e Nordeste para ambos os sexos. Assim, entre homens, o aumento mais expressivo deu-se na Região Nordeste $\left(\Delta_{\text {absoluto }}=21,3 ; \Delta_{\%}=35,5\right)$. Observou-se ainda, para esse grupo de causa, ausência de variação importante na razão de sexo entre as regiões do país no período considerado (Tabela 2 e Figura 1).

Já o DALY de homicídios/agressões entre homens reduziu somente, e de maneira marcada, no Sudeste $\left(\Delta_{\text {absoluto }}=-77,0 ; \Delta_{\%}=-39,9\right)$, aumentando intensamente no Nordeste $\left(\Delta_{\text {absoluto }}=65,1\right.$; $\left.\Delta_{\%}=64,5\right)$, Norte $\left(\Delta_{\text {absoluto }}=54,1 ; \Delta_{\%}=57,6\right)$ e Sul $\left(\Delta_{\text {absoluto }}=40,4 ; \Delta_{\%}=55,2\right)$; e entre as mulheres reduziu no Sudeste $\left(\Delta_{\text {absoluto }}=-6,3 ; \Delta_{\%}=-35,8\right) \mathrm{e}$ Centro-oeste $\left(\Delta_{\text {absoluto }}=-2,2 ; \Delta_{\%}=-13,0\right)$. Quanto à razão de sexo para homens, destaca-se acentuado aumento na Região Norte, passando de 8 para 12 no período estudado (Tabela 2 e Figura 1).

\section{Análise por faixa etária}

No que concerne às faixas etárias, pode-se verificar que existiu uma diminuição expressiva no DALY para os menores de 15 anos, passando de 13,1\%, em 1998, para 8,1\%, em 2008. É possível notar ainda que houve uma redistribuição para as faixas etárias mais elevadas, com destaque para o grupo de 45 a 59 anos, que passou de 10,8\% para $13,2 \%$ (Figura 3 ).

Os acidentes de trânsito apresentaram uma redução na taxa de DALY em todas as faixas etárias, com exceção para os indivíduos de 15 a 29 anos, em que se constatou um aumento relativo de $8,8 \%$. O mesmo comportamento acontece nas taxas de YLL. Enquanto para as taxas de YLD houve diminuição em todas as faixas etárias, sem exceção.

Os homicídios/agressões tiveram um ligeiro aumento para a faixa etária de 15 a 29 anos, de aproximadamente $1 \%$ para a taxa de DALY. Já pa- 


\section{Figura 1}

Distribuição do YLL (years of life lost), YLD (years lived with disability) e gênero segundo macrorregiões. Brasil, 1998 e 2008.

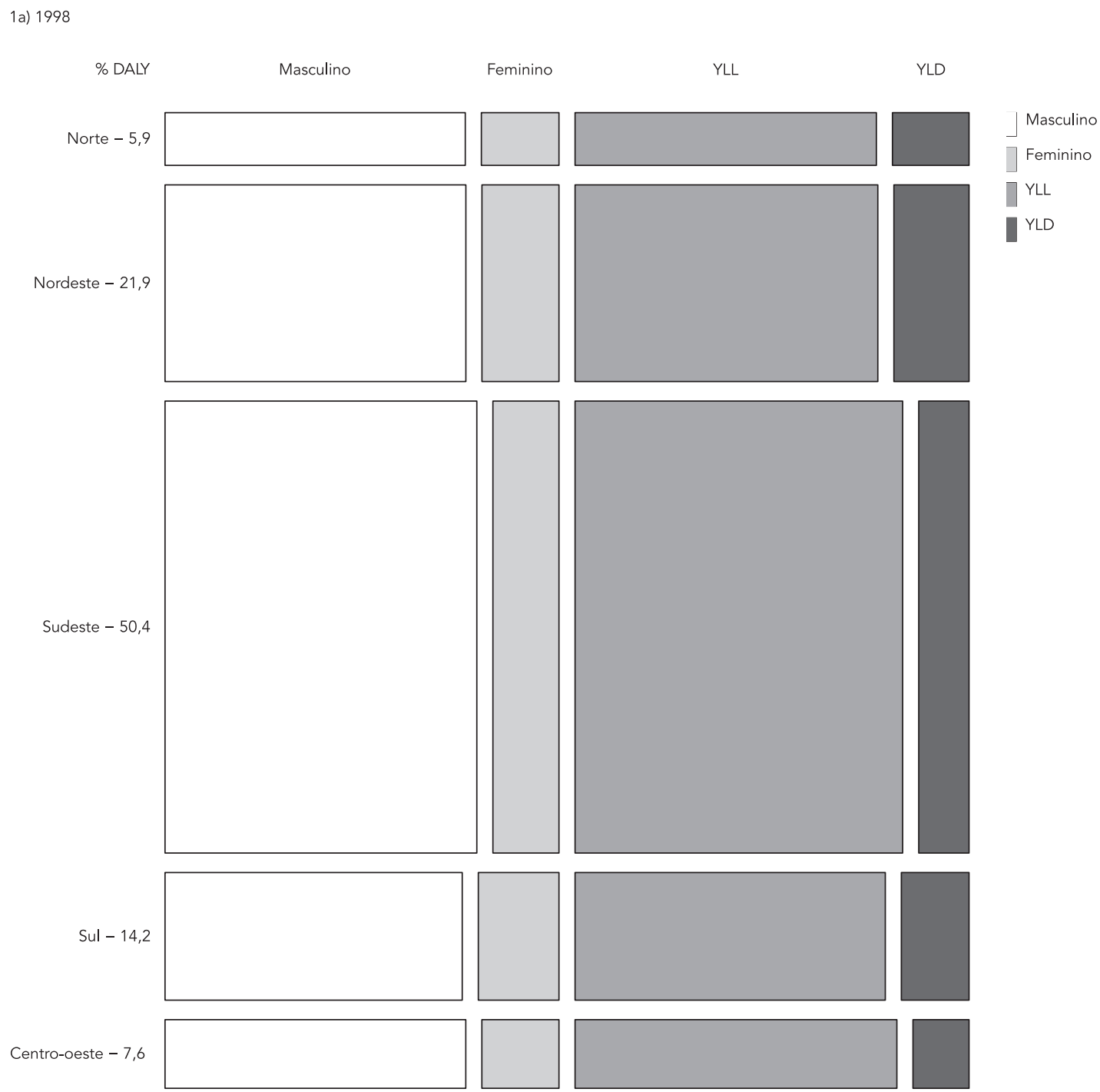

(continua)

ra o YLL, os menores de 15 anos também tiveram aumento $(4,6 \%)$. O YLD apresentou quedas relevantes para todas as faixas etárias, segundo essa causa (Figura 3).

As causas não intencionais tiveram quedas expressivas na taxa de DALY para todas as faixas etárias, sendo mais acentuada para a os menores de 15 anos (-35,5\%). As taxas de YLL e YLD tiveram comportamento similar ao do DALY, sendo maior redução de $-26,1 \%$ e $-48,5 \%$, respectivamente, também para os menores de 15 anos (Figura 3).
Já as causas intencionais apresentaram redução nas taxas de DALY para todas as faixas etárias, exceto para o grupo de 15 a 29 anos, que teve um aumento de 2,3\% no período estudado. As taxas de YLL aumentaram somente para os menores de 15 anos $(5,2 \%)$ e de 15 a 29 anos $(2,9 \%)$. $\mathrm{E}$ as taxas de YLD reduziram para todas as faixas etárias (Figura 3). 
1b) 2008

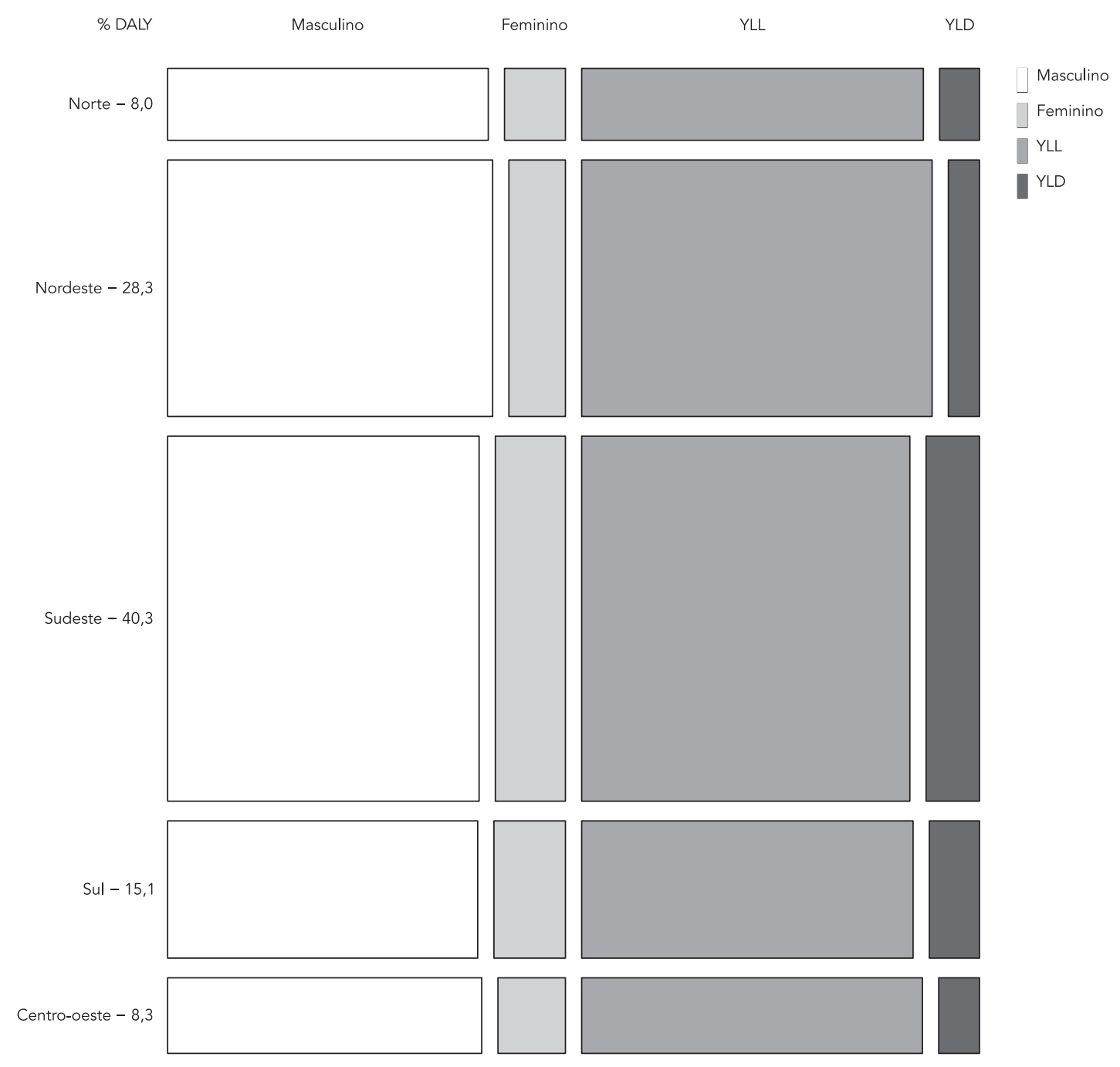

\section{Discussão}

As injúrias por causas externas foram responsáveis, no Brasil, por aproximadamente $10 \%$ do total da carga de doença estimada em 1998 e 2008. Com pequena diferença entre os anos, no mundo, esses agravos representaram $11 \%$ do total do DALY tanto no ano 2000 quanto em 201023. Assim como o Brasil, a África do Sul, que também compõe o BRICS, apresentou uma proporção abaixo da identificada para o mundo $(8,4 \%$ e $8,8 \%$ ), tendo a Rússia (19\% e 15\%), a China (14\% e
13\%) e a Índia (11\% e 12\%) com proporção maior ou semelhante à mundial. Já entre países membros da Organização para a Cooperação e Desenvolvimento Econômico (OCDE), como Noruega $(9,3 \%$ e $9,9 \%)$, Suécia $(9,1 \%$ e $9,2 \%)$ e Holanda $(8,3 \%$ e $8,1 \%)$ esse percentual ficou abaixo do identificado mundialmente.

De acordo com os resultados do presente estudo, os homicídios/agressões ocuparam, em ambos os anos estudados, o primeiro lugar no ranking das causas externas no país. Entre os BRICS, apenas a África do Sul apresentou pano- 


\section{Figura 2}

Distribuição do YLL (years of life lost), YLD (years lived with disability) e gênero segundo grupos de causas externas. Brasil, 1998 e 2008.

2a) 1998

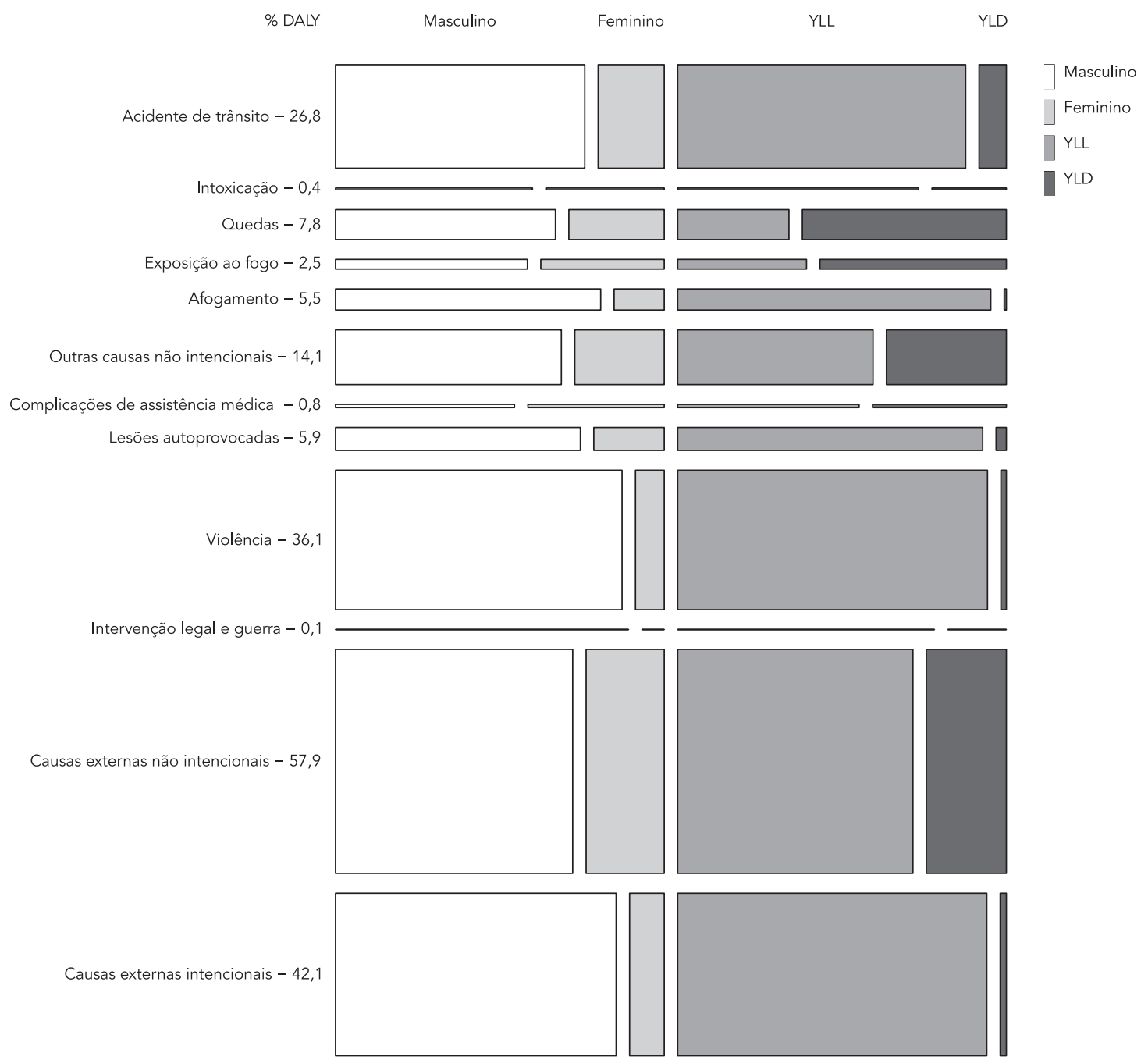

(continua)

rama semelhante, com esses agravos assumindo a maior parcela do DALY relacionado às causas externas, tanto em 2000 quanto em 2010 23. A taxa de DALY relacionada a esses agravos teve redução de aproximadamente $2 \%$ no período, no entanto atrai interesse que: (1) essa queda foi impulsionada unicamente pelo Sudeste, tendo havido aumentos expressivos em todas as demais regiões, em especial Norte, Nordeste e Sul; (2) os homicídios/agressões passaram a representar parcela ainda mais expressiva do total da carga relacionada às causas externas no país, aumentando de $36,1 \%$ para $38,9 \%$; (3) houve acréscimo do componente YLL (mortalidade) na composição do DALY relacionado a esses agravos; (4) a única faixa etária que apresentou elevação na taxa de DALY, ainda que em torno de $1 \%$, foi a dos jovens de 15 a 29 anos, justamente a mais atingida por tais eventos 5 .

Como possíveis explicações para a expressiva queda verificada na Região Sudeste para homicídios/agressões, pode-se citar a transferência 
2b) 2008

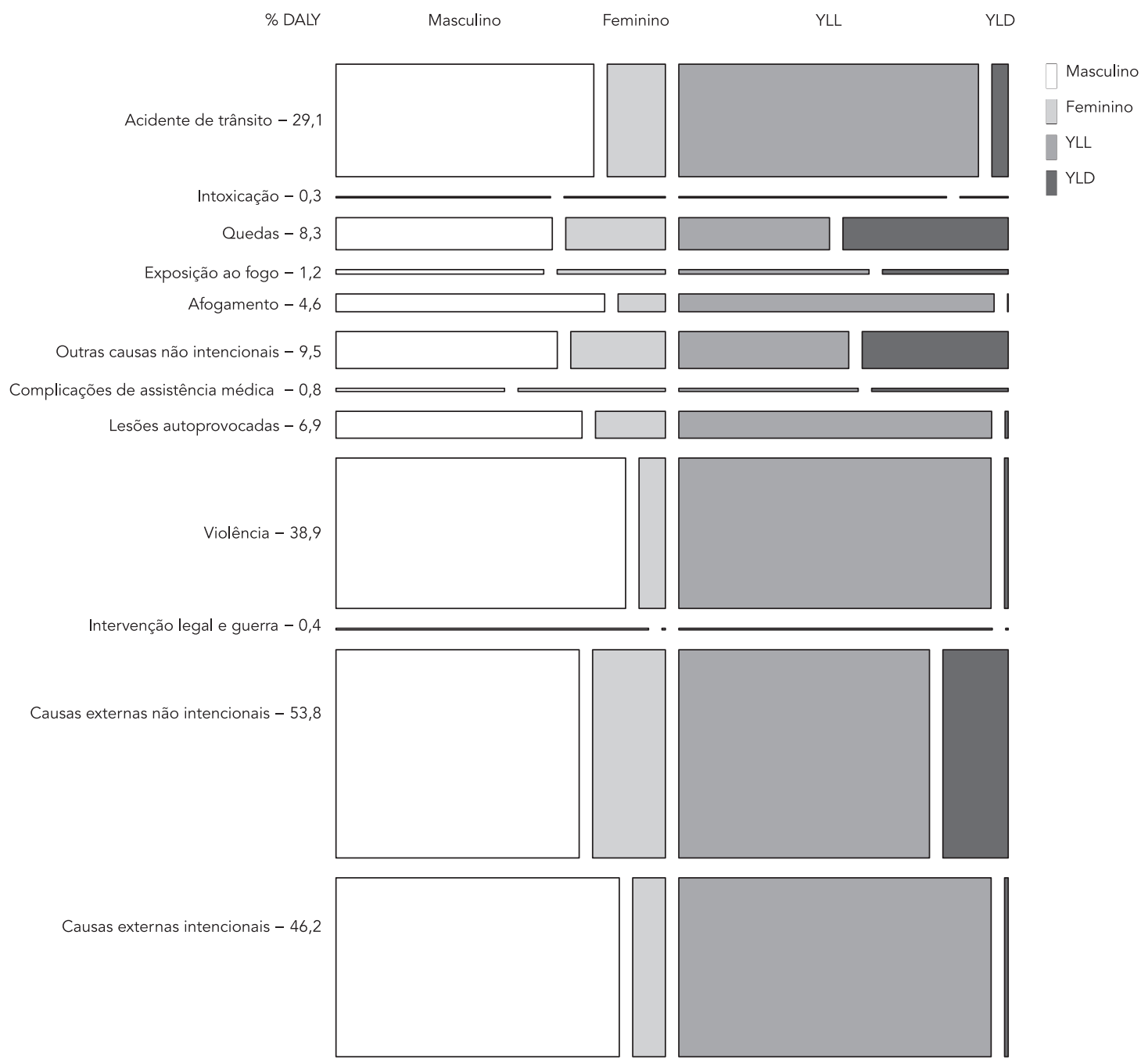

de recursos para o aparelhamento da segurança pública nas capitais e regiões metropolitanas assegurada pelo plano nacional de segurança pública de 1999 e o fundo nacional de segurança instituído em janeiro de 2001, além da campanha do desarmamento 24 , mais efetivo nessas regiões 5 . No sentido contrário, o elevado aumento dos homicídios/agressões identificado nas regiões Norte e Nordeste, pode estar ligado, entre outros fatores, ao processo de intensa urbanização ocorrido nos últimos anos no país que impulsionou a criação de novos polos econômicos nessas regiões então desprovidas de políticas de segurança pública e infraestrutura adequadas 5 . Pode-se apontar também a redução na subnotificação ocorrida nessas regiões. Igualmente, estudos assinalam a dinâmica demográfica como um importante fator explicativo. Por exemplo, no Estado de São Paulo, Mello \& Schneider 25 propuseram que aproximadamente metade das reduções nos índices de homicídios ocorridos nos últimos anos seria explicada pela aceleração do envelhecimento populacional, com declínio da população jovem, grupo mais vulnerável a sofrer os impactos da violência. 


\section{Figura 3}

Distribuição do YLL (years of life lost), YLD (years lived with disability) e gênero segundo faixa etária. Brasil, 1998 e 2008 (em anos).

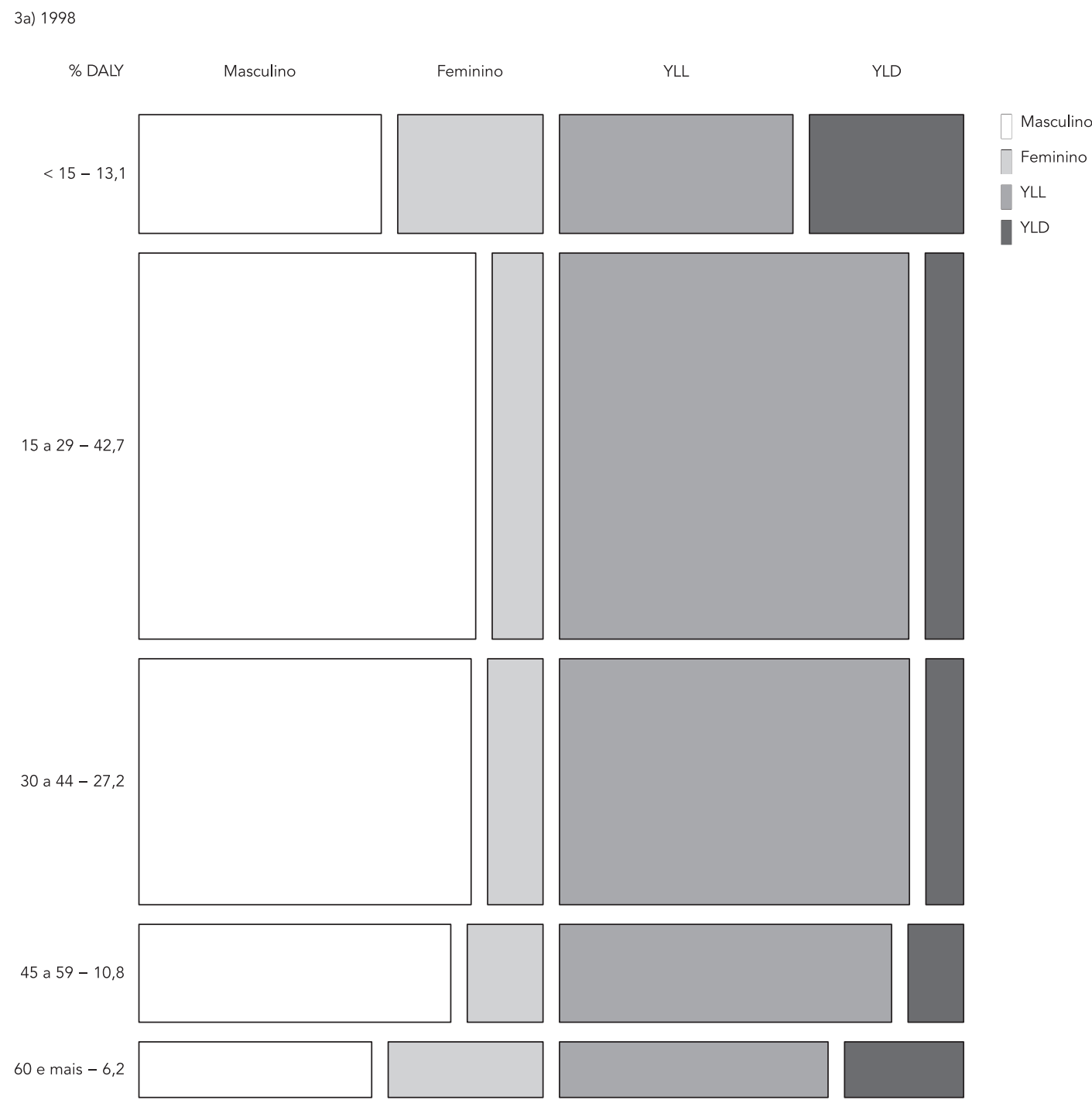

(continua)

Merece registro que, no período estudado, inúmeras estratégias em resposta aos homicídios/agressões foram conduzidas tanto na perspectiva da segurança quanto da saúde pública. Em nível federal, mencionam-se: (1) as políticas nacionais de "Redução da Morbimortalidade por Acidentes e Violências" 26 e de "Promoção da Saúde” 27 aprovadas pelo Ministério da Saúde , respectivamente em 2002 e 2006, com o principal objetivo de desenvolver ações voltadas tanto para o monitoramento e prevenção dos agravos quanto para a assistência e reabilitação das vítimas; (2) o Programa Nacional de Segurança Pública com Cidadania (PRONASCI) 28, instituído em 2007 pelo Ministério da Justiça, que busca desenvolver ações integradas nas áreas de segurança e sociais; e, (3) o já citado Estatuto do Desarmamento que entrou em vigor em 200324.

A causa que ocupou a segunda maior parcela do DALY relacionado às causas externas no Brasil, em ambos os anos analisados, foi acidentes de trânsito. No mundo, com destaque para al- 
3b) 2008

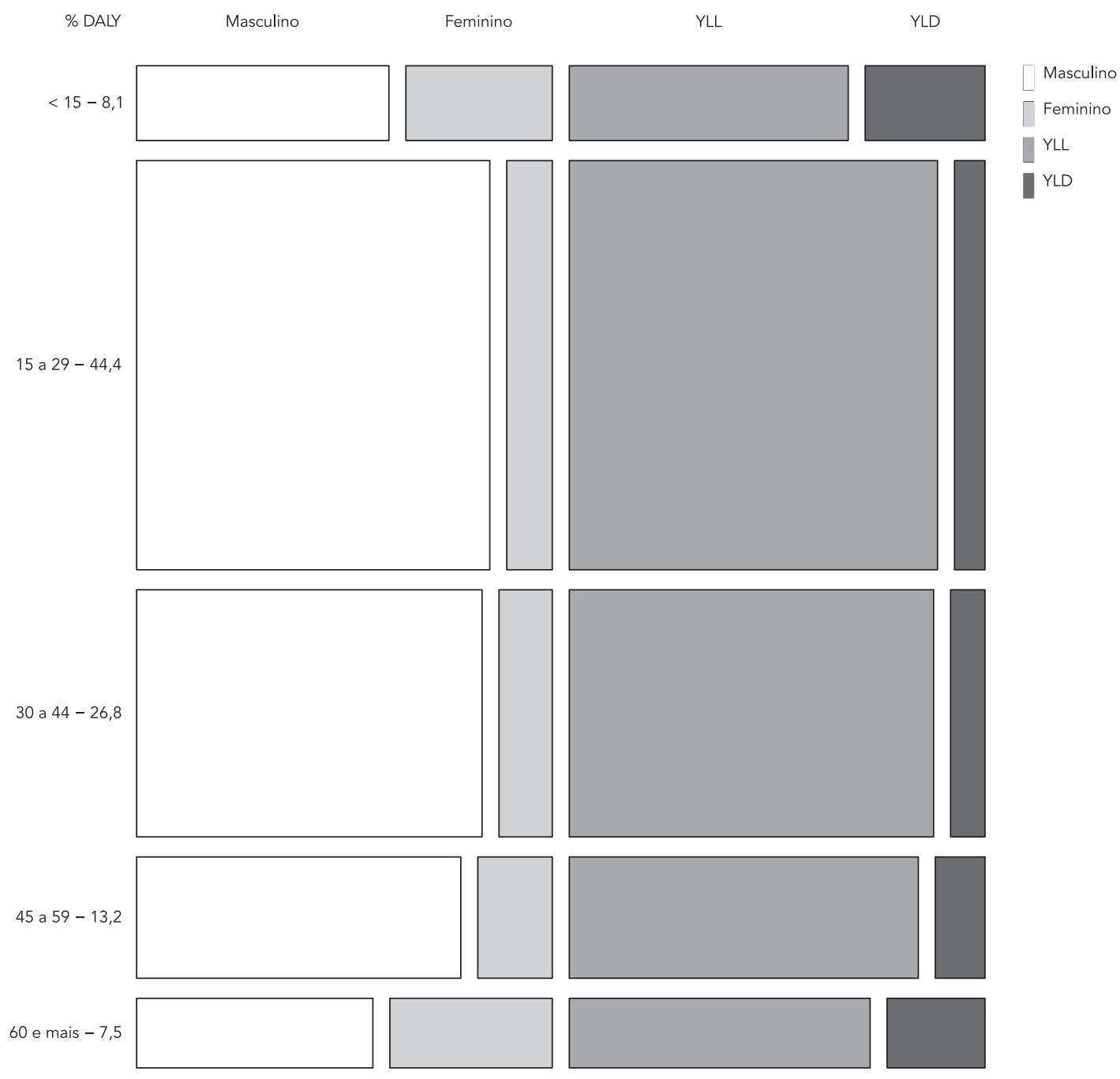

guns países como China e Índia, esses agravos foram os maiores responsáveis por anos de vida perdidos por injúrias, tanto em 2000 quanto 2010, sendo o mesmo para a Rússia, mas apenas em 2010 23. Apesar de ter havido queda na taxa do DALY relacionado aos acidentes de trânsito no país entre os anos 1998 e 2008, chama a atenção que: (1) houve aumento expressivo no DALY relacionado a esses acidentes nas regiões Norte e Nordeste; (2) a queda identificada no DALY deuse apenas no componente YLD (morbidade), tendo aumentado no componente YLL (mortalidade); (3) houve aumento na participação dos acidentes de trânsito no DALY total de causas externas, passando de $26,1 \%$ para $29,1 \%$. Quanto ao aumento dos óbitos, diferentes estudos com pequenas variações entre os anos analisados apontaram aumentos nas mortes relacionadas a acidentes de trânsito no país 11,29. Quanto ao tipo desses acidentes, o nível de agregação dos dados neste estudo não permitiu análises mais detalhadas, mas diferentes autores 11,29,30 apontam que os ocupantes de motocicletas têm representado parcela cada vez mais expressiva da morbimortalidade por esses agravos. 
Não por acaso, observa-se um contínuo crescimento no número de motocicletas no Brasil, que em 1998 representavam 11,5\% da frota, passando para 26,1\% em 2011 29. Nacionalmente, como estratégias para o enfrentamento dos acidentes de trânsito, merecem destaque: a aprovação do Novo Código de Trânsito Brasileiro 31 em 1998, com impactos imediatos na redução das internações hospitalares e nos óbitos, ainda que sem efeito continuado 30 ; a aprovação das já mencionadas políticas nacionais de redução da morbimortalidade por acidentes e violência 26 e promoção da saúde 27; a implantação, em 2002, do programa de Redução da Morbimortalidade por Acidentes de Trânsito - Mobilizando a Sociedade e Promovendo a Saúde 32; a aprovação da Lei no 11.705 33, a chamada "Lei Seca", no ano de 2008, com impactos na mudança de comportamento da população com relação ao consumo de álcool no trânsito e na redução das internações hospitalares e óbitos 30 e, por fim, a implantação em 2010, pelo Ministério da Saúde do programa Vida no Trânsito 34, inserido no contexto do projeto Road Safety in Ten Countries (RS 10) 35 coordenado pela Organização Mundial da Saúde (OMS) e como resposta às metas propostas pela Organização das Nações Unidas (ONU) para o período de 2011 a 2020, proclamado pela última como a década de ação pela segurança no trânsito 36 .

No Brasil, as quedas, em ambos os anos analisados, mantiveram-se como a quarta maior parcela do DALY relacionado às causas externas, logo atrás das "outras não intencionais". No mundo, esses agravos assumiram a terceira maior parcela e a primeira em países OCDE como Noruega, Holanda e Suécia, tanto em 2000 quanto em 2010 23. Igualmente, como identificado para os acidentes de trânsito e homicídios/agressões, no período analisado, a taxa de DALY relacionado às quedas reduziu no país como um todo. Todavia, vale destacar os seguintes pontos: (1) essa redução foi identificada unicamente no YLD, tendo havido aumento no componente de mortalidade YLL; (2) a estratificação por faixa etária mostra que os maiores aumentos ocorreram entre a população idosa geral (acima de 60 anos de idade), faixa etária em que esses eventos estão entre os principais causadores de incapacidade $\mathrm{e}$ morte 8 . Uma coorte realizada com 1.667 idosos residentes no Município de São Paulo mostrou que $30 \%$ deles sofreram quedas ao menos uma vez ao ano 20 . Fatores intrínsecos e extrínsecos predispõem às quedas em idosos. Entre os primeiros, incluem-se sedentarismo, autopercepção ruim da saúde, faixa etária mais elevada, uso de medicamentos, deficiências ocular, auditiva e cognitiva entre outros. Já os fatores extrínsecos relacionam-se ao ambiente em que vive o idoso e podem abarcar: piso escorregadio, tapetes soltos, iluminação inadequada, escadas, armários e interruptores fora do alcance etc. 8,9. As únicas regiões que apresentaram aumento nas taxas de DALY relacionadas a quedas no período foram o Centro-oeste e o Sudeste. Os homens apresentaram taxas de DALY mais elevadas para quedas em ambos os anos, mas chama a atenção que as reduções nas taxas entre eles foram mais incisivas. Além disso, considerando-se o total das causas externas, entre as mulheres as quedas são razoavelmente mais expressivas.

Os suicídios ocuparam o quinto lugar no ranking da carga relacionada às causas externas no Brasil, tanto em 1998 quanto em 2008. Já no mundo, esses agravos assumiram a segunda posição, e a terceira em países como Noruega, Holanda e Suécia, tanto em 2000 quanto em 201023. Apesar da baixa magnitude no país, registra-se que os suicídios foram a única causa externa com acréscimo na taxa de DALY no período estudado, tendo tais aumentos ocorrido unicamente nas regiões Norte e Nordeste e na faixa etária de 15 a 29 anos. A literatura também aponta elevação no número de suicídios entre jovens nessa década, mas em proporção menor que na população geral, especialmente a adulta ${ }^{5}$. Essa divergência deve-se provavelmente à composição do indicador DALY, já que os óbitos entre os jovens naturalmente contribuem com maior número de anos de vida perdidos.

Destaca-se que no período analisado a razão de sexo para os homens aumentou praticamente em todos os grupos de causas externas (exceto quedas e complicações da assistência médica). Estudos apontam que as taxas de mortalidade por causas externas acresceram essencialmente entre os homens nas últimas décadas 5,37 . Os homens apresentam sobremortalidade em todas as causas básicas e faixas etárias, o que impacta diretamente em maiores expectativas de vida entre as mulheres 38 . No Brasil, uma tentativa de resposta que merece registro foi a Política Nacional de Atenção Integral à Saúde do Homem 39 cujo objetivo é intervir favoravelmente nos indicadores de morbimortalidade, visando à melhora da expectativa e da qualidade de vida da população masculina.

As limitações do presente estudo referemse especialmente àquelas inerentes ao uso de sistemas de informação nacionais como base de dados secundários, tais como: o sub-registro de mortalidade para causas externas para o qual não existe correção ${ }^{40}$; a não cobertura de atendimentos hospitalares do setor privado ${ }^{41}$; e a ausência de inquérito anual de abrangência nacional sobre atendimento em emergência/ 
urgência. Além disso, consideram-se ainda aspectos relacionados ao próprio indicador DALY cujos pesos utilizados para cálculo da morbidade atualmente são pautados na gravidade das lesões por sexo e faixa etária 42. Esses pesos são padronizados mundialmente, não levando em conta as especificidades dos diferentes sistemas de saúde. Recentemente, alguns estudos vêm apresentando novas abordagens 43 .

As causas externas vêm se consolidando nas últimas décadas como um dos principais desafios para a saúde pública brasileira. Os resultados do presente estudo apontam redução, ainda que de baixa magnitude, na carga desses agravos na década analisada, provavelmente como efeito das políticas de enfrentamento adotadas. Contudo, são inúmeros os obstáculos que persis-

\section{Resumen}

El objetivo fue comparar las estimaciones de las causas externas desde el estudio Carga Global Enfermedades entre los años 1998/2008. La estimación de los DALY (disability-adjusted life year) e YLL (years of life lost) se basó en la metodología del estudio Carga Global de Enfermedades. Para el cálculo de YLD (years lived with disability), era necesario aplicar la misma metodología en ambos períodos, siendo elegido como el último punto de referencia. Pese a que en ambos períodos las causas externas fueron responsables de alrededor del $10 \%$ del total de DALY, su distribución interna mostró marcadas diferencias entre las regiones brasileñas con una caída en el Sudeste y un aumento en el Norte y Noreste. Se observó un aumento de causas intencionales y la YLL fue responsable de la mayor proporción de DALY en todos los grupos de causas externas. Se espera que estos resultados balicen la formulación de políticas y/o la mejora de las que ya existen, con el fin de hacer frente eficazmente a las causas externas.

Accidentes; Homicidio; Causas Externas; Costo de Enfermedad tem, e esses pequenos avanços estão longe de ser satisfatórios. Em termos de taxas, o Brasil segue com uma carga elevadíssima de causas externas, especialmente homicídios/agressões com pouquíssimos equivalentes internacionais, que afetam particularmente os jovens de sexo masculino. No Norte e Nordeste o crescimento acelerado das causas externas somado à elevada carga de doenças crônicas e das ainda persistentes doenças infectoparasitárias delineia um alarmante perfil de tripla carga nessas regiões ${ }^{44}$. Sendo as causas externas preveníveis, espera-se que os resultados deste estudo possam balizar a formulação de novas políticas e/ou o aprimoramento das já existentes, visando ao efetivo enfrentamento da questão.

\section{Colaboradores}

L. V. P. Mendes, M. R. Campos e V. R. von-Doellinger contribuíram na concepção, delineamento, redação, análise dos dados e revisão do artigo. J. C. Mota colaborou na redação, análise dos dados e revisão do artigo. T. G. Pimentel colaborou na montagem do banco de dados e análise dos resultados e revisão do artigo. J. M. A. Schramm participou no delineamento, redação e revisão do artigo.

\section{Agradecimentos}

Agradecemos ao Departamento de Ciência e Tecnologia do Ministério da Saúde pelo financiamento deste estudo; a toda equipe do Núcleo de Pesquisa em Métodos Aplicados aos Estudos de Carga Global de Doença, especialmente aos demais coordenadores Iuri Costa Leite e Joaquim Valente; e ao Ministério da Saúde, na pessoa da Dra. Deborah Carvalho Malta, diretora do Departamento de Análise de Situação de Saúde (Ministério da Saúde), pela disponibilização do banco de dados do VIVA Inquérito. 
1. Prata PR. A transição epidemiológica no Brasil. Cad Saúde Pública 1992; 8:168-75.

2. Schramm JMA, Oliveira AF, Leite IC, Valente JG, Campos MR, Gadelha AMJ, et al. Transição epidemiológica e o estudo de carga de doença no Brasil. Ciênc Saúde Coletiva 2004; 9:897-908.

3. Minayo MCS, Souza ER. Violência para todos. Cad Saúde Pública 1993; 9:65-78.

4. World Health Organization. World report on violence and health. Geneva: World Health Organization; 2002.

5. Waiselfisz JJ. Mapa da violência 2014: os jovens do Brasil. http://observatorio.c3sl.ufpr.br/xmlui/ handle/123456789/229 (acessado em 22/Abr/ 2014).

6. Vermelho LL, Mello-Jorge MHP. Mortalidade de jovens: análise do período de 1930 a 1991 (a transição epidemiológica para a violência). Rev Saúde Pública 1996; 30:319-31.

7. Couto FBD, Perracini MR. Análise multifatorial do perfil de idosos ativos com história de quedas. Rev Bras Geriatr Gerontol 2012; 15:693-706.

8. Wang S-Y, Wollin J. Falls among older people: identifying those at risk. Nurs Older People 2004; 15: 14-6.

9. Britton JW. Kids can't fly: preventing fall injuries in children. WMJ 2005; 104:33-6.

10. Paes CEN, Gaspar VLV. As injúrias não intencionais no ambiente domiciliar: a casa segura. J Pediatr (Rio J.) 2005; 81 Suppl 5:S146-54.

11. Moraes Neto OL, Montenegro MMS, Monteiro RA, Siqueira Júnior JB, Silva MMA, Lima CM, et al. Mortalidade por acidentes de transporte terrestre no Brasil na última década: tendência e aglomerados de risco. Ciênc Saúde Coletiva 2012; 17: 2223-36

12. Gawryszewski VP, Koizumi MS, Mello-Jorge MHP. As causas externas no Brasil no ano 2000: comparando a mortalidade e a morbidade. Cad Saúde Pública 2004; 20:995-1003.

13. Souza ER, Lima MLC. Panorama da violência urbana no Brasil e suas capitais. Ciênc Saúde Coletiva 2006; 11:1211-22.

14. Departamento de Análise de Situação de Saúde, Secretaria de Vigilância em Saúde, Ministério da Saúde. VIVA: Vigilância de Violências e Acidentes, 2008 e 2009. Brasília: Ministério da Saúde; 2010.

15. Murray CJL, Lopez AD. Global health statistics: a compendium of incidence, prevalence, and mortality estimates for over 200 conditions. Cambridge: Harvard University Press; 1996.

16. Murray CJL, Lopez AD. The global burden of disease: a comprehensive assessment of mortality and disability from diseases, injuries, and risk factors in 1990 and projected to 2020. Cambridge: Harvard University Press; 1996.

17. Murray CJL, Ezzati M, Flaxman AD, Lim S, Lozano R, Michaud C, et al. GBD 2010: a multi-investigator collaboration for global comparative descriptive epidemiology. Lancet 2012; 380:2055-8.

18. World Health Organization. The global burden of disease: 2004 update. Geneva: World Health Organization; 2008.
19. von Doellinger VR, Campos MR, Mendes LVP, Schramm JMA. The 2008 Global Burden of Disease study in Brazil: a new methodological approach for estimation of injury morbidity. Rev Panam Salud Pública 2014; 36:368-75.

20. Organização Mundial da Saúde. Classificação Estatística Internacional de Doenças - CID-10. 10a rev. v. 1. São Paulo: Edusp; 1994.

21. Coale A, Guo G. Revised regional model life tables at very low levels of mortality. Popul Index 1989; 55:613-43.

22. Gadelha AMJ, Leite IC, Valente JG, Schramm JMA, Portela MC, Campos MR. Relatório final do projeto Estimativa da Carga de Doença do Brasil. Rio de Janeiro: Escola Nacional de Saúde Pública Sergio Arouca, Fundação Oswaldo Cruz; 2002.

23. Institute for Health Metrics and Evaluation. Global Burden of Diseases, Injuries, and Risk Factors Study 2010 (GBD 2010). http://www.healthmetricsandevaluation.org/gbd/visualizations/regional (acessado em 16/Out/2013).

24. Presidência da República. Lei no 10.826, de 22 de dezembro de 2003. Dispõe sobre registro, posse e comercialização de armas de fogo e munição, sobre o Sistema Nacional de Armas - Sinarm, define crimes e dá outras providências. Diário Oficial da União 2003; $23 \mathrm{dez}$.

25. Mello JMP, Schneider A. Mudança demográfica e a dinâmica dos homicídios no Estado de São Paulo. São Paulo Perspect 2007; 21:19-30.

26. Ministério da Saúde. Portaria GM/MS no 737, de 16 de maio de 2001. Institui a Política Nacional de Redução da Morbimortalidade por Acidentes e Violências. Diário Oficial da União 2001; 18 mai.

27. Ministério da Saúde. Portaria GM/MS no 687, de 30 de março de 2006. Aprova a Política Nacional de Promoção da Saúde. Diário Oficial da União 2006; 31 mar.

28. Ministério da Justiça. Lei no 11.530 , de 24 de outubro de 2007. Institui o Programa Nacional de Segurança Pública com Cidadania - PRONASCI e dá outras providências. Diário Oficial da União 2007; 25 out.

29. Waiselfisz JJ. Mapa da violência 2013: acidentes de trânsito e motocicletas. http://observatorio.c3sl. ufpr.br/xmlui/handle/123456789/229 (acessado em 22/Abr/2014).

30. Bacchieri G, Barros AJ. Acidentes de trânsito no Brasil de 1998 a 2010: muitas mudanças e poucos resultados. Rev Saúde Pública 2011; 45:949-63.

31. Brasil. Lei no 9.503, de 23 de setembro de 1997. Institui o Código de Trânsito Brasileiro. Diário Oficial da União 1997; 24 set.

32. Ministério da Saúde. Portaria GM/MS no 344, de 19 de fevereiro de 2002. Aprova o Projeto de Redução da Morbimortalidade por Acidentes de Trânsito - Mobilizando a Sociedade e Promovendo a Saúde. Diário Oficial da União 2002; 20 fev.

33. Presidência da República. Lei no 11.705, de 19 de junho de 2008. Inibe o consumo de bebida alcoólica por condutor de veículo automotor, e dá outras providências. Diário Oficial da União 2008; 20 jun. 
34. Silva MMA, Morais Neto OL, Lima CM, Malta DC, Silva Junior JB. Projeto Vida no Trânsito - 2010 a 2012: uma contribuição para a Década de Ações para a Segurança no Trânsito 2011-2020 no Brasil. Epidemiol Serv Saúde 2013; 22:531-6.

35. Hyder AA, Bishai D. Road safety in 10 countries: a global opportunity. Traffic Inj Prev 2012; 13 Suppl $1: 1-2$.

36. World Health Organization. Global plan for the decade of action for road safety 2011-2020. Geneva: World Health Organization; 2010.

37. Minayo MCS. Seis características das mortes violentas no Brasil. Rev Bras Estud Popul 2009; 26:135-40.

38. Laurenti R, Mello-Jorge MHP, Gotlieb SLD. Perfil epidemiológico da morbimortalidade masculina. Ciênc Saúde Coletiva 2005; 10:35-46.

39. Secretaria de Atenção à Saúde, Ministério da Saúde. Política Nacional de Atenção Integral à Saúde do Homem. Brasília: Ministério da Saúde; 2008.

40. Costa MFS. Anos de vida perdidos por morte prematura: o efeito de diferentes critérios de correção de sub-registro [Dissertação de Mestrado]. Rio de Janeiro: Escola Nacional de Saúde Pública Sergio Arouca, Fundação Oswaldo Cruz; 2007.
41. Rede Interagencial de Informações para a Saúde. Ficha de qualificação da cobertura de planos de saúde. Cobertura de planos de saúde - F.15 - 2011. http://www.ripsa.org.br/fichasIDB/record.php?n ode=f.15\&lang=pt\&version=ed6 (acessado em 25/ Out/2013).

42. Mathers C, Vos T, Stevenson C. The burden of disease and injury in Australia - summary report. Canberra: Australian Institute of Health and Welfare; 1999.

43. Lyons RA, Kendrick D, Towner EM, Christie N, Macey S, Coupland C, et al. Measuring the population burden of injuries: implications for global and national estimates. A multi-centre prospective UK Longitudinal Study. PLoS Med 2011; 8:e1001140.

44. Leite IC, Valente JG, Schramm JMA. Relatório final do projeto Carga de Doença do Brasil, 2008. Rio de Janeiro: Escola Nacional de Saúde Pública Sergio Arouca, Fundação Oswaldo Cruz; 2013.

Recebido em 05/Set/2014

Versão final reapresentada em 10/Fev/2015

Aprovado em 02/Mar/2015 